\title{
The Danger of "Mask-Related Spectacle Fogging" in the Time of COVID-19
}

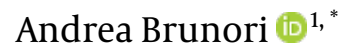 \\ ${ }^{1}$ San Camillo Hospital, Rome, Italy \\ "Corresponding author: MD, Consultant Neurosurgeon, San Camillo Hospital, Circonvallazione Gianicolense 87, Rome, Italy. Email: andrea.brunori65@gmail.com \\ Received 2020 May 27; Accepted 2020 June 20.
}

Keywords: Neurosurgery, Spine Injuries, Mask, COVID-19, Pandemia, SARS-CoV-2

\section{Dear Editor,}

The dramatic outbreak of SARS-CoV-2 urged the worldwide application of preventing measures, such as social distancing, hand hygiene, and mask-wearing. Even mere speech generates potentially deadly droplets (1). Face covering, a widespread habit in Asian countries with underlying environmental and social reasons, is instead totally new to Italy. The monthly demand for Italian health care providers is estimated at 130 million pieces per month, but millions more are needed for the general population. The shortage is a constant threat. Except for sick, infected individuals live-in or health care workers, surgical masks and "respirators" (N95 and similar) are not recommended for others (2). Most people ignore that valve respirators, perceived by the layman as the most sophisticated and "stylish" ones, only protect wearer, but not others, from the transmission. A comfortable and cheap homemade cloth face covering as the one crafted in a popular video tutorial by the US Surgeon General is suitable in most daily activities. Besides shortage, mask misuse has potential dangers: reduction of oxygen intake, being a source of infection if reused, and last but not the least spectacle fogging. More than $41 \%$ of Italians wear prescription lenses. Concomitant use of masks, especially respirators, may cause warm exhaled air to condense on cooler lens surfaces. Light scattering by droplets results in reduced visual acuity, a major hazard in any scenario requiring optimal vision such as urban driving (Figure 1).

Traffic accidents are the first death cause in Italy for people aged 15 - 44. The national quarantine declared on March 9, 2020, dramatically restricted mobility with few exceptions (necessity, work, health). Monday traffic on six major routes in Rome dropped from 15\% on March 9, to 75\% on March 23 (https://romamobilita.it/it/covid-19-impattosulla-mobilita). Heavy road patrolling also prompted responsible driving. Accordingly, road accidents in Rome decreased in March 2020 compared to 2019 by 64\%, and injuries and deaths by $72.4 \%$ and $91 \%$, respectively (3). Similar data have been reported on suburban roads. In the "post-peak" period, road traffic will slowly grow back to usual, but masks will become compulsory for all, including drivers. Local authorities in Lombardy and Tuscany (with more evaluations) introduced a $€ 400$ fine for offenders. Rational, individualized use of face masks should be strongly encouraged. People should also be aware of "side effects", including lens fogging. How to deal with it? Some simple tips are learned by experience (tissue inside the top of the mask, molding to the nose by tape, etc.). Others come from health professionals: washing lenses with soapy water (4) and backhead cross tying the laces, creating lateral vents to evacuate warm moist breath (5). More are welcome. These simple tricks will help save lives, prevent severe disabilities, and contain the costs of our already strained national health systems.

\section{Footnotes}

Conflict of Interests: The author declared no conflict of interest.

Funding/Support: No funding/support is reported by the author. 

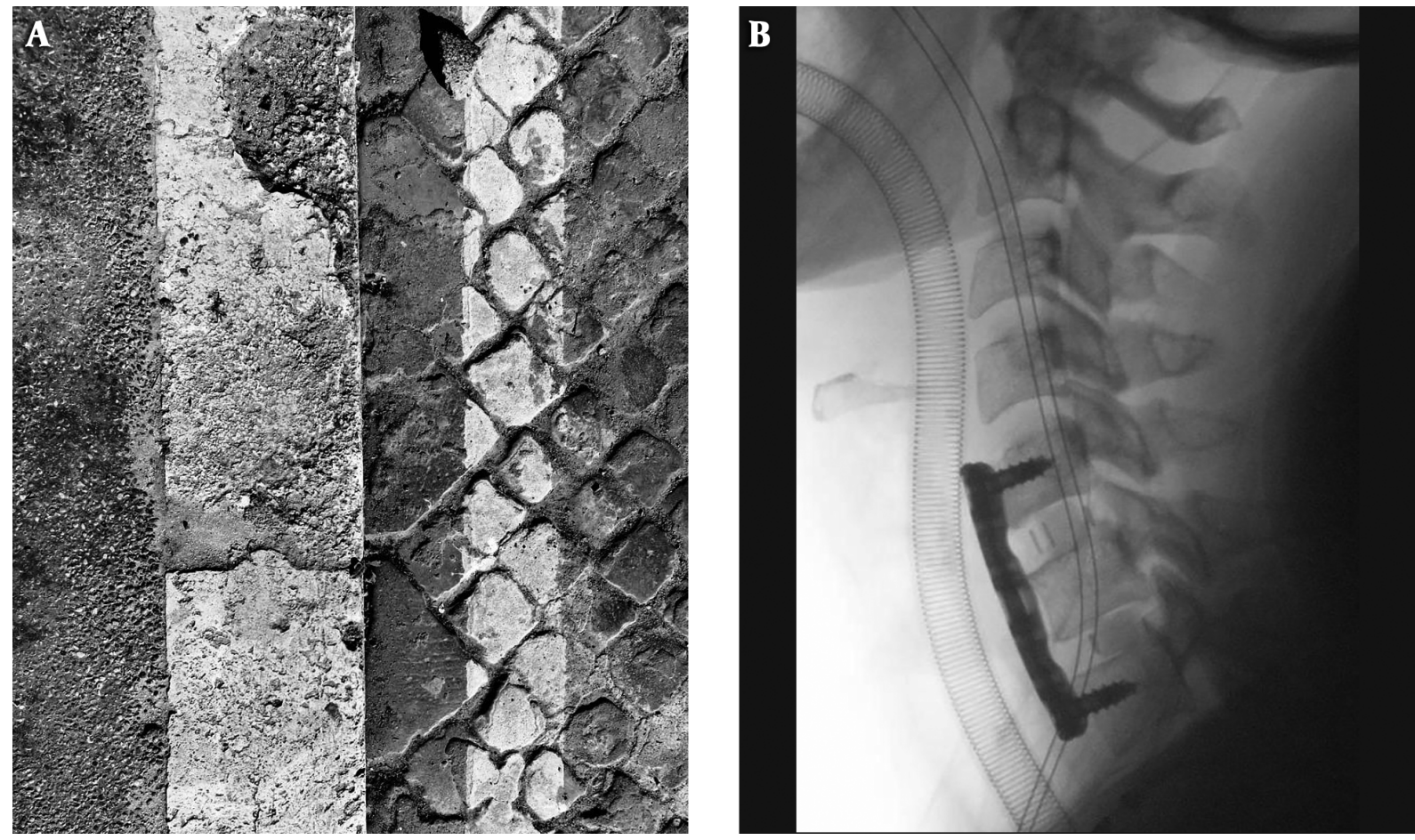

Figure 1. A, a 34-year-old young lady wearing a jet helmet, spectacles, and an N95 type mask was driving her scooter back home from food shopping, one of the few legal activities during the lockdown. Persistent, intense lens fogging in the morning chill hampered her vision; she hit a travertine curb typical of Roman sidewalks, lost control of the vehicle, and suffered major polytrauma. B, the patient underwent emergency surgery for cervical trauma ( $\mathrm{C} 5$ - $\mathrm{C} 7$ fusion and plating to decompress the cord and stabilization) and multiple closed leg fractures. Following hospitalization, the patient was discharged to a rehabilitation hospital for further treatment.

\section{References}

1. Anfinrud P, Stadnytskyi V, Bax CE, Bax A. Visualizing SpeechGenerated Oral Fluid Droplets with Laser Light Scattering. $N$ Engl J Med. 2020;382(21):2061-3. doi: 10.1056/NEJMc2007800. [PubMed: 32294341]. [PubMed Central: PMC7179962].

2. Desai AN, Aronoff DM. Masks and Coronavirus Disease 2019 (COVID19). JAMA. 2020. doi: 10.1001/jama.2020.6437. [PubMed: 32301960].

3. Pirone D. Coronavirus con il lockdown gli incidenti stradali giù del $60 \%$. In due mesi circa 400 morti e migliaia di feriti in meno. Il Messaggero; 2020.
Italian.

4. Malik SS, Malik SS. A simple method to prevent spectacle lenses misting up on wearing a face mask. Ann R Coll Surg Engl. 2011;93(2):168. doi: 10.1308/003588411X12851639107313c. [PubMed: 22041151]. [PubMed Central: PMC3293317].

5. Jordan DJ, Pritchard-Jones R. Tying a surgical mask to prevent fogging. Ann R Coll Surg Engl. 2014;96(2):165. doi: 10.1308/rcsann.2014.96.2.165. [PubMed: 24780682]. [PubMed Central: PMC4474252]. 